\title{
Improvement of psychological status after infliximab treatment in patients with newly diagnosed Crohn's disease
}

This article was published in the following Dove Press journal:

Patient Preference and Adherence

\author{
Maochen Zhang* \\ Tianyu Zhang* \\ Liwen Hong \\ Chen Zhang \\ Jie Zhou \\ Rong Fan \\ Lei Wang \\ Zhengting Wang \\ Bin Xu \\ Jie Zhong
}

Department of Gastroenterology, Ruijin Hospital, Shanghai Jiao Tong University School of Medicine,

Shanghai, People's Republic of China

*These authors contributed equally to this work
Correspondence: Jie Zhong; Bin Xu Department of Gastroenterology, Ruijin Hospital, Shanghai Jiao Tong University School of Medicine, No 197, Ruijiner Road, Shanghai 200025, People's Republic of China

Tel +86 2l 64370045 (ext 600907) Email jimmyzj64@medmail.com.cn; dr.binxu@vip.163.com
Background: Patients with newly diagnosed Crohn's disease (CD) are associated with impaired physical and psychological well-being. These psychological characteristics are dynamic with the course of disease and could be influenced by medical treatment. Infliximab is effective and widely used in moderate-to-severe CD patients. The aim of this study was to evaluate the improvement of psychological status after infliximab treatment in patients with newly diagnosed CD.

Methods: Newly diagnosed moderate-to-severe CD patients were prospectively enrolled in our study. Infliximab $5 \mathrm{mg} / \mathrm{kg}$ was administered at weeks $0,2,6,14,22$, and 30 . Outcomes including disease severity, illness perceptions, coping strategies, anxiety, depression, and quality of life (QoL) were measured at baseline, week 14, and week 30.

Results: Eighty-two patients completed our study. The rates of clinical remission at weeks 14 and 30 were 59/82 (72.0\%) and 58/82 (70.7\%), respectively. Patients who achieved clinical remission at weeks 14 and 30 significantly improved in illness perceptions $(P<0.001$ and $<0.001)$, maladaptive coping $(P=0.005$ and 0.004$)$, anxiety $(P<0.001$ and $<0.001)$, depression $(P=0.004$ and 0.004$)$, and QoL $(P<0.001$ and $<0.001)$. However, emotion-focused coping and problem-focused coping remained unchanged. For infliximab nonresponders, no significant changes were seen in illness perceptions, coping strategies, anxiety, depression, or QoL at week 14 or 30 .

Conclusion: Effective infliximab treatment not only led to clinical remission in patients with newly diagnosed moderate-to-severe $\mathrm{CD}$ but also improved their psychological status including illness perceptions, maladaptive coping, anxiety, depression, and QoL.

Keywords: illness perceptions, coping strategies, anxiety and depression, quality of life, infliximab

\section{Introduction}

Crohn's disease (CD) is a chronic inflammatory disorder characterized by discontinuous inflammation that can occur anywhere in gastrointestinal tract, predominantly in the small intestine and the colon. As a chronic disease, CD brings physical, psychological, and social impairments to patients, which would pose negative effects on their lives in all aspects. ${ }^{1-3}$ It is reported that quality of life (QoL) is reduced in CD patients compared to healthy controls. ${ }^{4,5}$ Moreover, high levels of anxiety and depression are inconvenient truths in CD patients. ${ }^{6}$

It has been shown that psychological distress and QoL are not only associated with the disease severity itself but also associated with factors such as illness perceptions and coping strategies, which is supported by the Common Sense Model (CSM). ${ }^{7}$ Illness perceptions are individual's mental representations of their disease, while 
coping strategies are defined as the ways that an individual manages or deals with stress. ${ }^{8}$ According to the CSM, patients generate cognitive representations based on the disease threat they are faced with. Patients would form illness perceptions in response to disease severity, which in turn may influence coping strategies and finally the illness outcomes such as psychological health and QoL.9,10 Therefore, disease severity, illness perceptions, coping strategies, psychological well-being, and QoL are significantly associated with each other. ${ }^{8,11,12}$

For newly diagnosed CD patients, a complex psychological adaption occurs in a very short time, including emotional responses such as distress and guilt and behavioral responses such as seeking social support, taking new medication, and evaluating the disease's impact on life. This adaption is dynamic with the unpredictable changes of disease progression since patients may experience ongoing physical and psychological challenges. ${ }^{13}$

The treatment target for CD patients is to induce and maintain long-term remission. As a proinflammatory cytokine, tumor necrosis factor- $\alpha$ (TNF- $\alpha$ ) plays an important role in the pathogenesis of CD. Infliximab is the humanmurine chimera anti-TNF- $\alpha$ monoclonal antibody, which can bind to TNF- $\alpha$ with high affinity and neutralize its biological activity. Therefore, infliximab tends to alleviate patient's symptoms quickly due to its prompt anti-inflammatory effect. Moreover, infliximab is by now the only anti-TNF- $\alpha$ agent available for us which is approved by China Food and Drug Administration (CFDA) for CD. ${ }^{14,15}$

Up till now, there are many cross-sectional studies on psychological well-being in CD patients, but it lacks prospective follow-up studies. Besides, most research focuses on remission rates after infliximab administration, while improvement of psychological status remains little known. This study was aimed to evaluate the changes of illness perceptions, coping strategies, psychological well-being (anxiety and depression), and QoL in patients with newly diagnosed $\mathrm{CD}$ after infliximab induction therapy.

\section{Patients and methods}

\section{Patients}

Newly diagnosed CD patients in Ruijin Hospital from September 1, 2014 to December 31, 2016 were prospectively enrolled. Inclusion criteria were as follows: 1) having Harvey-Bradshaw Index $(\mathrm{HBI})^{16,17}$ score $>4$; 2) receiving infliximab as induction therapy; and 3) willing to answer the questionnaires at baseline, week 14, and week 30 after intervention independently and voluntarily. Exclusion criteria were as follows: 1) used CD-related medication before; 2) with contraindications of infliximab such as infection and stricture; 3 ) history of mental disease or psychological intervention before; and 4) with other chronic diseases.

This study was approved by the Ethics Committee of Ruijin Hospital affiliated to Shanghai Jiao Tong University School of Medicine, and written informed consent was signed by each patient.

\section{Methods}

At baseline, disease severity was measured using HBI, and patients were asked to fill a questionnaire measuring psychological characteristics. Then, a dose of $5 \mathrm{mg} / \mathrm{kg}$ intravenous infusion with infliximab was applied at weeks $0,2,6,14$, 22 , and 30 . The disease activity was re-evaluated at weeks 14 and 30. Clinical remission was defined as a HBI score of $\leq 4$. Meanwhile, patients were asked to fill out the same questionnaires. All the questionnaires were completed in our hospital, and patients were encouraged to finish the questionnaires within 30 minutes.

\section{Questionnaires}

\section{Illness perceptions}

The Brief Illness Perceptions Questionnaire ${ }^{18}$ is a validated 9-item scale evaluating patient's perceptions of overall effect of the disease, including consequences, timeline, personal control, treatment control, identity, concern, understanding, and emotional response. These items are scored on a continuous $0-10$ scale, with higher total scores representing poorer illness perceptions.

\section{Coping strategies}

The Brief Coping Operations Preference Enquiry ${ }^{19}$ is a validated 28-item questionnaire to assess coping behaviors, which are divided into adaptive problem-focused coping (active coping, planning, and using instrumental support), adaptive emotion-focused coping (positive reframing, acceptance, humor, religion, and using emotional support), and maladaptive coping (self-distraction, denial, venting, substance use, behavioral disengagement, and self-blame). ${ }^{20}$ Each item is measured with a scale ranging from 0 to 3 , with higher scores indicating that particular coping strategies are more adopted.

\section{Anxiety and depression}

The Hospital Anxiety and Depression Scale (HADS) ${ }^{21}$ is a 14-item tool (seven items for a separate anxiety score and seven items for a separate depression score) to measure individual's emotional adjustment. Each item is assessed on 
a 4-point scale. Total scores of either anxiety or depression range from 0 to 21 , higher scores representing higher levels of anxiety or depression.

\section{QoL}

The Inflammatory Bowel Disease Questionnaire ${ }^{22}$ is a disease-specific, health-related QoL questionnaire, containing 32 items, with a graded response range of 1-7 and a total score range of 32-224, with lower scores indicating poorer QoL.

\section{Statistical analysis}

The paired $t$-test was used to calculate changes in the questionnaire measures from baseline to week 14 and from baseline to week 30 after treatment. Statistical significance was considered if the calculated two-tailed $P$-value was $<0.05$. SPSS 21.0 was used to perform all the data analyses.

\section{Results}

A flow diagram of our study is shown in Figure 1. We found that of the 98 participants who met our inclusion criteria and filled out our baseline questionnaires, 87 patients completed questionnaires at week 14. Four patients experienced severe side effects to infliximab (two for allergy and the other two for myelosuppression) that treatment had to be terminated. Seven patients did not return the follow-up questionnaires. At week 30, 82 patients completed our questionnaires. One patient dropped out because of myelosuppression, and four patients did not complete follow-up assessment. Finally, 82 patients finished our study. The demographic characteristics of the final cohort are shown in Table 1.

Fifty-nine of the $82(72.0 \%)$ patients achieved clinical remission at week 14, with HBI decreasing from $6.24 \pm 1.68$ to $2.42 \pm 1.00(P<0.001)$. Changes in psychological parameters of these patients are shown in Table 2. Patients made significant improvement in illness perceptions $(P<0.001)$, maladaptive coping $(P=0.005)$, anxiety $(P<0.001)$, depression $(P=0.004)$, and QoL $(P<0.001)$. At week 30, 58/82 (70.7\%) patients were in clinical remission, whose HBI decreased from $6.40 \pm 1.70$ to $2.26 \pm 1.12(P<0.001)$. As shown in Table 2, patients made significant improvement in illness perceptions $(P<0.001)$, maladaptive coping $(P=0.004)$, anxiety $(P<0.001)$, depression $(P=0.004)$, and QoL $(P<0.001)$, compared with those at baseline. However, emotion-focused coping and problem-focused coping remained unchanged at week 14 or 30 .

Meanwhile, 23/82 (28.0\%) and 24/82 (29.3\%) patients did not achieve clinical remission at weeks 14 and 30, respectively. For these infliximab nonresponders, their psychological characteristics including illness perceptions, coping strategies, anxiety, depression, and QoL achieved no significant improvement after treatment, which are shown in Table 3.

\section{Discussion}

This study aimed to determine the changes of psychological parameters in newly diagnosed CD patients after infliximab

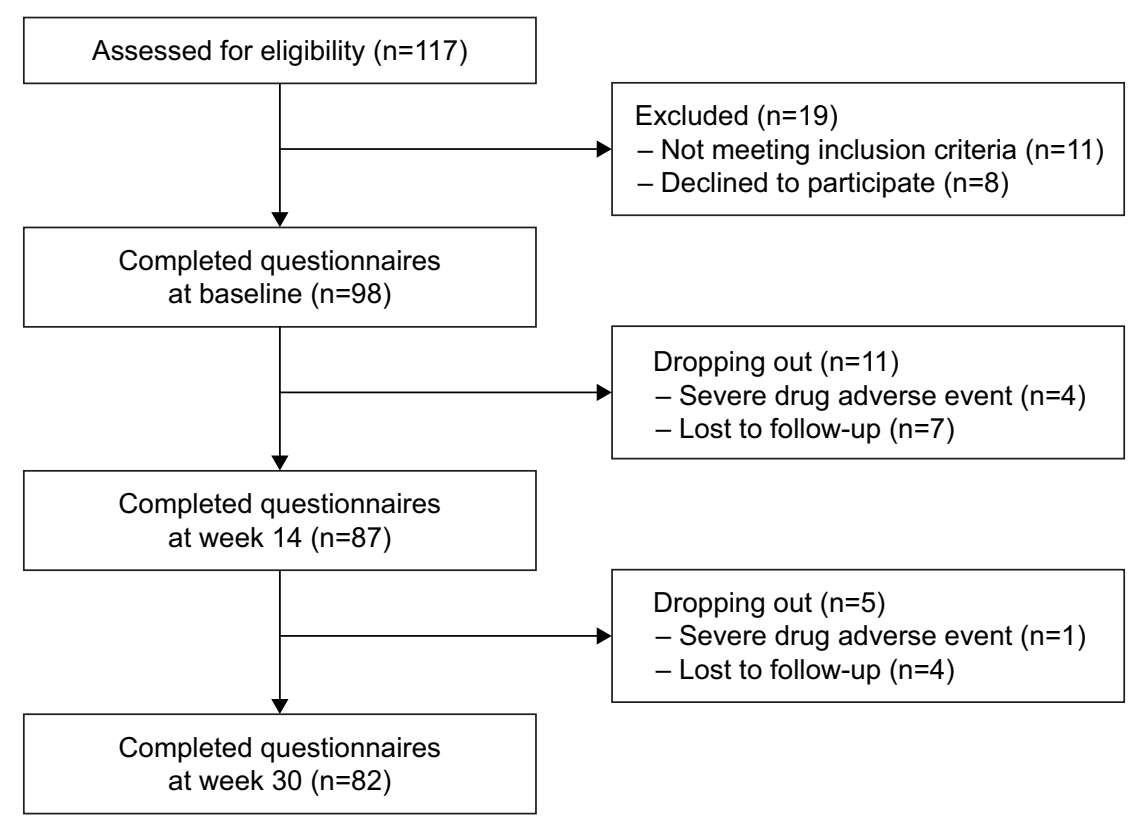

Figure I Participant flow diagram. 
Table I Demographics of participants

\begin{tabular}{ll}
\hline Variable & $\mathbf{n}(\%)$ \\
\hline Gender & \\
Male & $45(54.9)$ \\
Female & $37(45.1)$ \\
Marital status & \\
$\quad$ Married & $57(69.5)$ \\
$\quad$ Single & $25(30.5)$ \\
Age at diagnosis (A) & \\
$\quad$ I6 years (AI) & $0(0.0)$ \\
I7-40 years (A2) & $60(73.2)$ \\
$>40$ years (A3) & $22(26.8)$ \\
Location (L) & \\
Terminal ileum (LI) & $35(42.7)$ \\
Colon (L2) & $17(20.7)$ \\
Ileocolon (L3) & $30(36.6)$ \\
Upper gastrointestinal tract (L4) & $5(6.1)$ \\
Behavior (B) & \\
Nonpenetrating nonstenosing (BI) & $7 \mathrm{I}(86.6)$ \\
Stenosing (B2) & $0(0.0)$ \\
Penetrating (B3) & $1 \mathrm{I}(\mathrm{I} 3.4)$ \\
Fistula history & $33(40.2)$ \\
Gastrointestinal surgery history & $9(\mathrm{I} 3.1)$ \\
Smoking or alcohol history & $12(9.2)$ \\
IBD family history & $3(2.3)$ \\
\hline Abbreviation &
\end{tabular}

Abbreviation: IBD, inflammatory bowel disease.

treatment. We found that patients who achieved clinical remission had significantly improved illness perceptions, decreased adoption of maladaptive coping strategies, lower levels of anxiety and depression, and better QoL. However, no improvement in psychological parameters was seen in infliximab nonresponders.

As a simple tool to evaluate disease activity for $C D$ patients, HBI decreased significantly after induction treatment in our study. Meanwhile, most patients achieved clinical remission, which was similar to previous research. ${ }^{23-27}$ Infliximab is effective in improving symptoms and alleviating disease severity for CD patients. ${ }^{14}$

Inflammatory bowel disease (IBD) patients with impaired psychological health and decreased QoL were highly associated with strong belief that IBD would have negative consequences for their life. ${ }^{7}$ Our study found that with the improvement of disease severity after induction treatment, patient's illness perceptions improved as well, which was consistent with previous research. ${ }^{28-31}$ However, follow-up study of illness perceptions is little known among IBD patients, which still needs further exploring.

In our study, maladaptive coping decreased significantly after effective treatment for patients achieved clinical remission, while no such changes were seen in emotion-focused coping or problem-focused coping. It could be explained by the previous evidence indicating maladaptive coping is significantly associated with individual's physical status and psychological status. ${ }^{8,11,13,20,32}$ As patients become healthier through medical interventions, the need to cope with difficult situations significantly decreases. Nevertheless, a recent longitudinal study evaluating changes of coping strategies in newly diagnosed IBD patients showed different results. ${ }^{20}$ They found that maladaptive coping did not change with time. In their research, most patients were treated with 5-aminosalicylic acid and immunomodulators, with very few patients treated with corticosteroids and no one used antiTNF- $\alpha$ agents. However, in our study, all the participants were treated with infliximab, which was thought to be a rapid and effective medication in $\mathrm{CD}$ treatment. This might explain why our patients acquired better improvement and used fewer maladaptive coping strategies after treatment.

Patients' anxiety and depression also decreased significantly after treatment in our cohort. Similar to our results, the study by Calvet et $\mathrm{al}^{33}$ showed that patient's psychological distress improved greatly and restored to normal levels after 6-month remission, but the research by McCombie et $\mathrm{al}^{20} \mathrm{did}$ not find improvement in anxiety or depression after 6-month treatment. Casellas et a ${ }^{34}$ suggested that the recovery of emotional impairment was delayed compared with the recovery of function on physical and social dimensions. Another interesting finding about psychological issues in our study was that although both anxiety and depression improved significantly after treatment, the extent of improvement in anxiety seemed

Table 2 Infliximab responders: significance of change in questionnaire scores

\begin{tabular}{|c|c|c|c|c|c|c|}
\hline Variable & Baseline, $n=59$ & Week I4, n=59 & $P$-value & Baseline, $n=58$ & Week 30, n=58 & $P$-value \\
\hline Illness perceptions & $44.59 \pm 12.23$ & $36.75 \pm 12.01$ & $<0.001$ & $45.22 \pm 12.07$ & $35.47 \pm 11.30$ & $<0.001$ \\
\hline Emotion-focused coping & $18.46 \pm 5.16$ & $|9.42 \pm 4.4|$ & 0.063 & $17.95 \pm 4.95$ & $18.59 \pm 5.19$ & 0.337 \\
\hline Problem-focused coping & $14.19 \pm 2.75$ & $13.86 \pm 3.07$ & 0.346 & $14.07 \pm 2.77$ & $13.60 \pm 3.64$ & 0.329 \\
\hline Maladaptive coping & $11.95 \pm 6.43$ & $9.97 \pm 6.25$ & 0.005 & $11.78 \pm 6.59$ & $9.67 \pm 6.18$ & 0.004 \\
\hline Anxiety & $10.02 \pm 2.14$ & $8.44 \pm 1.64$ & $<0.00$ I & $10.03 \pm 2.09$ & $8.16 \pm 1.82$ & $<0.001$ \\
\hline Depression & $9.05 \pm 2.46$ & $8.10 \pm 2.08$ & 0.004 & $9.00 \pm 2.36$ & $8.02 \pm 1.95$ & 0.004 \\
\hline Quality of life & $153.66 \pm 27.06$ & $|87.4| \pm 22.54$ & $<0.001$ & $|5| .38 \pm 26.66$ & $192.10 \pm 23.11$ & $<0.001$ \\
\hline
\end{tabular}

Note: Data shown as mean \pm standard deviation or $P$-value. 
Table 3 Infliximab nonresponders: significance of change in questionnaire scores

\begin{tabular}{|c|c|c|c|c|c|c|}
\hline Variable & Baseline, $n=23$ & Week I4, n=23 & $P$-value & Baseline, $\mathrm{n}=\mathbf{2 4}$ & Week 30, n=24 & $P$-value \\
\hline Illness perceptions & $51.13 \pm 9.57$ & $49.13 \pm 11.93$ & 0.170 & $49.33 \pm 11.06$ & $47.79 \pm 10.95$ & 0.391 \\
\hline Emotion-focused coping & $19.61 \pm 4.73$ & $17.87 \pm 4.77$ & 0.053 & $20.79 \pm 4.78$ & $19.54 \pm 4.96$ & 0.346 \\
\hline Problem-focused coping & $|4.6| \pm 2.7 \mid$ & $|3.39 \pm 3.3|$ & 0.111 & $|4.88 \pm 2.6|$ & $13.63 \pm 3.32$ & 0.121 \\
\hline Maladaptive coping & $13.57 \pm 5.92$ & $12.39 \pm 5.16$ & $0.24 I$ & $13.92 \pm 5.35$ & $12.54 \pm 5.70$ & 0.097 \\
\hline Anxiety & $10.57 \pm 2.11$ & $10.26 \pm 2.20$ & 0.573 & $10.50 \pm 2.23$ & $9.83 \pm 1.47$ & 0.141 \\
\hline Depression & $8.83 \pm 2.04$ & $9.13 \pm 2.40$ & 0.585 & $8.96 \pm 2.33$ & $9.75 \pm 2.31$ & 0.089 \\
\hline Quality of life & $137.48 \pm 24.24$ & $|46.17 \pm 23.4|$ & 0.104 & $143.67 \pm 28.13$ & $\mid 49.42 \pm 21.79$ & 0.284 \\
\hline
\end{tabular}

Note: Data shown as mean \pm standard deviation or $P$-value.

to be greater. This is probably because patient's HADSAnxiety scores were much higher than HADS-Depression scores before treatment in our research, indicating that more CD patients were in anxiety rather than depression. ${ }^{11}$

One of the primary treatment purposes of chronic diseases is the improvement of patient's QoL. From the perspective of QoL, an ideal result after treatment should be that patients achieved similar scores in QoL compared with general people. In our study, participants achieving clinical remission reported significant improvement in QoL after treatment, which is in good agreement with previous studies. ${ }^{35-42}$ Moreover, research demonstrated that the early restoration of the QoL after induction treatment in patients with $\mathrm{CD}$ was associated with prolonged remission in the future. ${ }^{43}$ Unconscious little alterations in QoL often reflect individual's general well-being, sometimes even before the appearance of obvious symptoms. The QoL has shown to be very sensitive to detect early changes of disease activity. Therefore, regular evaluation of QoL is quite meaningful, which can effectively predict the activity of the disease in the long term and discover early signs of disease flares. ${ }^{43-45}$

Our study found that patient's physical and psychological features including disease severity, illness perceptions, maladaptive coping, anxiety, depression, and QoL changed with time, which is in accordance with the CSM theory. ${ }^{9,10}$ As the disease activity decreased, patient's disease cognition and management, psychological status, and QoL improved at the same time, suggesting that disease stimuli, illness perceptions, coping strategies, and illness outcomes had complex interrelationships. ${ }^{8,11,12}$

There were some limitations in our study. First of all, we used HBI to assess our patient's disease severity, which mainly represent their clinical symptoms rather than mucosal healing (MH). Research showed that MH was associated with future hospitalization and surgery; thus, it was an important parameter in evaluating patient's health status. ${ }^{46-48}$ Therefore, evaluation of both clinical and endoscopic disease severities would be a more accurate way of reflecting patient's disease status. Second, number of flares, changes in laboratory results, and dosage changes in medication were not recorded in our study. These data may reflect patient's disease status, which could have an influence on patient's psychological characteristics. Third, all the patients in our study received infliximab treatment, while medications such as 5-aminosalicylic acid, steroids, and immunomodulators were not included. Studies on the comparison of patient's psychological changes between different treatments could be made in the future. Finally, we re-evaluated patient's physical and psychological parameters only at weeks 14 and 30. Several studies suggested that effective treatment brought benefits to CD patients both in the short term and up to 1 year, even as long as 4 years. ${ }^{23,39,42,43,49,50}$ We should make more frequent and longer follow-ups in further studies.

\section{Conclusion}

Newly diagnosed CD patients achieving clinical remission after effective infliximab treatment reported improved illness perceptions, maladaptive coping, anxiety, depression, and QoL. Interventions that help reduce patient's disease activity might also be beneficial to the improvement of their psychological characteristics.

\section{Acknowledgments}

This study was supported by the National Natural Science Foundation of China (numbers 81670503 and 81602558) and the Shanghai Committee of Science and Technology Foundation (numbers 16411950408 and 15ZR1426400).

\section{Disclosure}

The authors report no conflicts of interest in this work.

\section{References}

1. Casellas F, Arenas JI, Baudet JS, et al. Impairment of health-related quality of life in patients with inflammatory bowel disease: a Spanish multicenter study. Inflamm Bowel Dis. 2005;11(5):488-496.

2. Vergara M, Montserrat A, Casellas F, et al. A new validation of the Spanish Work Productivity and Activity Impairment QuestionnaireCrohn's disease version. Value Health. 2011;14(6):859-861. 
3. Sorensen VZ, Olsen BG, Binder V. Life prospects and quality of life in patients with Crohn's disease. Gut. 1987;28(4):382-385.

4. Drossman DA, Patrick DL, Mitchell CM, Zagami EA, Appelbaum MI. Health-related quality of life in inflammatory bowel disease. Functional status and patient worries and concerns. Dig Dis Sci. 1989;34(9): 1379-1386.

5. Irvine EJ. Quality of life issues in patients with inflammatory bowel disease. Am J Gastroenterol. 1997;92(12):18s-24s.

6. Goodhand JR, Wahed M, Mawdsley JE, Farmer AD, Aziz Q, Rampton DS. Mood disorders in inflammatory bowel disease: relation to diagnosis, disease activity, perceived stress, and other factors. Inflamm Bowel Dis. 2012;18(12):2301-2309.

7. van der Have M, Brakenhoff LK, van Erp SJ, et al. Back/joint pain, illness perceptions and coping are important predictors of quality of life and work productivity in patients with inflammatory bowel disease: a 12-month longitudinal study. J Crohns Colitis. 2015;9(3):276-283.

8. Knowles SR, Cook SI, Tribbick D. Relationship between health status, illness perceptions, coping strategies and psychological morbidity: a preliminary study with IBD stoma patients. J Crohns Colitis. 2013; 7(10):e471-e478.

9. Leventhal H, Meyer D, Nerenz D. The common sense model of illness danger. In: Petrie K, Weinman J, editors. Perceptions of Health and Illness. Amsterdam: OPA; 1980:19-46.

10. Hagger MS, Orbell S. A meta-analytic review of the common-sense model of illness representations. Psychol Health. 2003;18:141-184.

11. Zhang M, Hong L, Zhang T, et al. Illness perceptions and stress: mediators between disease severity and psychological well-being and quality of life among patients with Crohn's disease. Patient Prefer Adherence. 2016;10:2387-2396.

12. Knowles SR, Wilson JL, Connell WR, Kamm MA. Preliminary examination of the relations between disease activity, illness perceptions, coping strategies, and psychological morbidity in Crohn's disease guided by the common sense model of illness. Inflamm Bowel Dis. 2011;17(12):2551-2557.

13. Kiebles JL, Doerfler B, Keefer L. Preliminary evidence supporting a framework of psychological adjustment to inflammatory bowel disease. Inflamm Bowel Dis. 2010;16(10):1685-1695.

14. Siegel CA. What options do we have for induction therapy for Crohn's disease? Dig Dis. 2010;28(3):543-547.

15. Travis SP, Stange EF, Lemann M, et al. European evidence based consensus on the diagnosis and management of Crohn's disease: current management. Gut. 2006;55(Suppl 1):i16-i35.

16. Harvey RF, Bradshaw JM. A simple index of Crohn's-disease activity. Lancet. 1980;1(8167):514.

17. Best WR, Becktel JM, Singleton JW, Kern F Jr. Development of a Crohn's disease activity index. National Cooperative Crohn's Disease Study. Gastroenterology. 1976;70(3):439-444.

18. Broadbent E, Petrie KJ, Main J, Weinman J. The brief illness perception questionnaire. J Psychosom Res. 2006;60(6):631-637.

19. Carver CS. You want to measure coping but your protocol's too long: consider the brief COPE. Int J Behav Med. 1997;4(1):92-100.

20. McCombie AM, Mulder RT, Gearry RB. Coping strategies and psychological outcomes of patients with inflammatory bowel disease in the first 6 months after diagnosis. Inflamm Bowel Dis. 2015;21(10):2272-2280.

21. Zigmond AS, Snaith RP. The hospital anxiety and depression scale. Acta Psychiatr Scand. 1983;67(6):361-370.

22. Guyatt G, Mitchell A, Irvine EJ, et al. A new measure of health status for clinical trials in inflammatory bowel disease. Gastroenterology. 1989; 96(3):804-810.

23. Rutgeerts P, Feagan BG, Lichtenstein GR, et al. Comparison of scheduled and episodic treatment strategies of infliximab in Crohn's disease. Gastroenterology. 2004;126(2):402-413.

24. Lonnkvist MH, Befrits R, Lundberg JO, et al. Infliximab in clinical routine: experience with Crohn's disease and biomarkers of inflammation over 5 years. Eur J Gastroenterol Hepatol. 2009;21(10): $1168-1176$.
25. Fan R, Zhong J, Wang ZT, et al. Evaluation of "top-down" treatment of early Crohn's disease by double balloon enteroscopy. World $J$ Gastroenterol. 2014;20(39):14479-14487.

26. Colombel JF, Reinisch W, Mantzaris GJ, et al. Randomised clinical trial: deep remission in biologic and immunomodulator naive patients with Crohn's disease - a SONIC post hoc analysis. Aliment Pharmacol Ther. 2015;41(8):734-746.

27. Choi CH, Song ID, Kim YH, et al. Efficacy and safety of infliximab therapy and predictors of response in Korean patients with Crohn's disease: a nationwide, multicenter study. Yonsei Med J. 2016;57(6):1376-1385.

28. Tribbick D, Salzberg M, Connell W, et al. Differences across illness perceptions in inflammatory bowel disease and their relationships to psychological distress and quality of life. Gastroenterol Nurs. 2017; 40(4):291-299.

29. Dorrian A, Dempster M, Adair P. Adjustment to inflammatory bowel disease: the relative influence of illness perceptions and coping. Inflamm Bowel Dis. 2009;15(1):47-55.

30. Rochelle TL, Fidler H. The importance of illness perceptions, quality of life and psychological status in patients with ulcerative colitis and Crohn's disease. J Health Psychol. 2013;18(7):972-983.

31. van der Have M, Minderhoud IM, Kaptein AA, et al. Substantial impact of illness perceptions on quality of life in patients with Crohn's disease. J Crohns Colitis. 2013;7(8):e292-e301.

32. Knowles SR, Gass C, Macrae F. Illness perceptions in IBD influence psychological status, sexual health and satisfaction, body image and relational functioning: a preliminary exploration using Structural Equation Modeling. J Crohns Colitis. 2013;7(9):e344-e350.

33. Calvet X, Gallardo O, Coronas R, et al. Remission on thiopurinic immunomodulators normalizes quality of life and psychological status in patients with Crohn's disease. Inflamm Bowel Dis. 2006;12(8): 692-696.

34. Casellas F, López-Vivancos J, Badia X, Vilaseca J, Malagelada JR. Influence of inflammatory bowel disease on different dimensions of quality of life. Eur J Gastroenterol Hepatol. 2001;13(5):567-572.

35. Casellas F, López-Vivancos J, Badia X, Vilaseca J, Malagelada JR. Impact of surgery for Crohn's disease on health-related quality of life. Am J Gastroenterol. 2000;95(1):177-182.

36. Lichtenstein GR, Bala M, Han C, DeWoody K, Schaible T. Infliximab improves quality of life in patients with Crohn's disease. Inflamm Bowel Dis. 2002;8(4):237-243.

37. Cadahia V, Garcia-Carbonero A, Vivas S, et al. Infliximab improves quality of life in the short-term in patients with fistulizing Crohn's disease in clinical practice. Rev Esp Enferm Dig. 2004;96(369-374):74-78.

38. Delaney CP, Kiran RP, Senagore AJ, et al. Quality of life improves within 30 days of surgery for Crohn's disease. J Am Coll Surg. 2003;196(5): 714-721.

39. van Balkom BP, Schoon EJ, Stockbrugger RW, et al. Effects of antitumour necrosis factor-alpha therapy on the quality of life in Crohn's disease. Aliment Pharmacol Ther. 2002;16(6):1101-1107.

40. Thomsen OO, Cortot A, Jewell D, et al. Budesonide and mesalazine in active Crohn's disease: a comparison of the effects on quality of life. Am J Gastroenterol. 2002;97(3):649-653.

41. Irvine EJ, Greenberg GR, Feagan BG, et al. Quality of life rapidly improves with budesonide therapy for active Crohn's disease. Canadian Inflammatory Bowel Disease Study Group. Inflam Bowel Dis. 2000;6(3): 181-187.

42. Otley AR, Griffiths AM, Hale S, et al. Health-related quality of life in the first year after a diagnosis of pediatric inflammatory bowel disease. Inflamm Bowel Dis. 2006;12(8):684-691.

43. Herrera-deGuise C, Casellas F, Robles V, Navarro E, Borruel N. Predictive value of early restoration of quality of life in Crohn's disease patients receiving antitumor necrosis factor agents. $J$ Gastroenterol Hepatol. 2015;30(2):286-291.

44. Mittermaier C, Dejaco C, Waldhoer T, et al. Impact of depressive mood on relapse in patients with inflammatory bowel disease: a prospective 18-month follow-up study. Psychosom Med. 2004;66(1):79-84. 
45. Camara RJ, Juillerat P, Pittet V, et al. Quality of life: a potentially useful measure to indicate subclinical flares in Crohn disease. Intern Med J. 2012;42(7):e145-e151.

46. Rutgeerts P, Diamond RH, Bala M, et al. Scheduled maintenance treatment with infliximab is superior to episodic treatment for the healing of mucosal ulceration associated with Crohn's disease. Gastrointest Endosc. 2006;63(3):433-442. quiz 64.

47. Froslie KF, Jahnsen J, Moum BA, Vatn MH. Mucosal healing in inflammatory bowel disease: results from a Norwegian population-based cohort. Gastroenterology. 2007;133(2):412-422.
48. Schnitzler F, Fidder H, Ferrante M, et al. Mucosal healing predicts long-term outcome of maintenance therapy with infliximab in Crohn's disease. Inflamm Bowel Dis. 2009;15(9):1295-1301.

49. Hanauer SB, Feagan BG, Lichtenstein GR, et al. Maintenance infliximab for Crohn's disease: the ACCENT I randomised trial. Lancet. 2002;359(9317):1541-1549.

50. Casellas F, Rodrigo L, Niño P, Pantiga C, Riestra S, Malagelada JR. Sustained improvement of health-related quality of life in Crohn's disease patients treated with infliximab and azathioprine for 4 years. Inflamm Bowel Dis. 2007;13(11):1395-1400.

\section{Publish your work in this journal}

Patient Preference and Adherence is an international, peer-reviewed, open access journal that focuses on the growing importance of patient preference and adherence throughout the therapeutic continuum. Patient satisfaction, acceptability, quality of life, compliance, persistence and their role in developing new therapeutic modalities and compounds to optimize clinical outcomes for existing disease states are major areas of interest for the journal. This journal has been accepted for indexing on PubMed Central. The manuscript management system is completely online and includes a very quick and fair peer-review system, which is all easy to use. Visit http://www. dovepress.com/testimonials.php to read real quotes from published authors.

\footnotetext{
Submit your manuscript here: http://www.dovepress.com/patient-preference-and-adherence-journal
} 